https://doi.org/10.18485/iipe_postkovid.2021.ch4

\title{
EVROPSKA UNIJA USLED GLOBALNOG „GEOPOLITIČKOG LOCKDOWN-A“ I POČETAK PROCESA STRATEŠKE REINDUSTRIJALIZACIJE EU
}

\begin{abstract}
Neven CVETIĆANIN ${ }^{1}$
Apstrakt: Rad predstavlja analizu dominantnih geopolitičkih procesa u Evropi u vremenu pandemije Kovid 19, s namerom da se ti procesi stave u objektivan globalni geopolitički kontekst. U tom smislu se kao glavna geopolitička posledica pandemije Kovid 19 u Evropi i svetu prepoznaje proces povratka tzv. real-politike, tj. politike moći u svetske odnose, što je vidljivo iz procesa tzv. „geopolitičkog zaključavanja" (geopolitical lockdown) kojim je praćena pandemija Kovid 19 u svetu. U radu se istražuju posledice ovog procesa po Evropu, Balkan i posebno po kapacitet Evropske unije za proširenje. Stoga analiza ponuđena u ovom radu može biti korisna za dodatno konceptualizovanje strategije Republike Srbije u njenom odnosu prema Evropskoj uniji i osmišljavanje optimalnog pristupa procesu evropskih integracija, s obzirom na moguća dešavanja u Evropi nakon pandemije Kovid 19.

Ključne reči: Evropa/EU, pandemija, Kovid 19, posledice, geopolitika, zaključavanje (lockdown), real-politika, Balkan, Srbija, proširenje EU.
\end{abstract}

\section{Uvod}

Rad pred nama predstavlja pokušaj da se nakon prvih „talasa“ i „sojeva“ pandemije Kovid 19 u Evropi i širom sveta ponudi objektivna analiza dominantnih društvenih i političkih procesa na našem kontinentu i na području

\footnotetext{
${ }^{1}$ Viši naučni saradnik, Institut društvenih nauka, Beograd, viši naučni saradnik, e-mail: nevencveticanin@gmail.com

Rad je napisan u okviru Programa istraživanja Instituta društvenih nauka za 2021. godinu, koji podržava Ministarstvo prosvete, nauke i tehnološkog razvoja.
} 
Balkana kao njegovom specifičnom delu, kao i da se ti procesi stave $u$ objektivan globalni post-Kovid geopolitički kontekst. ${ }^{2}$

Glavna teza ovog rada jeste da je pandemija Kovid 19 doprinela povratku tzv. real-politike (Realpolitik) u svetske odnose, što je vidljivo pre svega u odnosima između velikih sila koje se usled panemdemije Kovid 19 vraćaju tzv. politici moći (Machtpolitik), što je posebno uočljivo u tzv. „geopolitici vakcina“, svojevrsnom geopolitičkom nadmetanju u kome velike sile sopstvenu sposobnost da prozivedu i distribuiraju vakcine koriste kao sredstvo geopolitičkog uticaja. ${ }^{3}$ Stoga možemo tvrditi da je tzv. „globalni lockdown“, izazvan pandemijom Kovid 19, zapravo svojevrsni geopolitički lockdown koji je doprineo zaokruživanju i "zatvaranju“ različitih geopolitičkih celina (veleprostora) u generalnom procesu u kojem međunarodni odnosi mutiraju ka čistoj geopolitici. Rad pred nama pokušaće da istraži kakva je pozicija Evrope kao kontinenta u ovom procesu „povratka geopolitike“ i kako se ovaj proces odražava na region Balkana.

Ujedno, rad će nastojati da, na ograničenom prostoru jednog naučnog članka, istraži kakva je pozicija Evropske unije kao panevropskog institucionalnog poretka u ovom procesu „povratka geopolitike“ koji trenutno maršira odbacujući sve ideološke maske, kakva je pozicija Republike Srbije u ovom procesu, kao i njene evropske perspektive, koja nesumnjivo zavisi od širih međunarodnih zbivanja.

Rad se sastoji iz dva dela. Prvi će biti posvećen Evropi i njenoj poziciji unutar najnovijih geopolitičkih zbivanja izazvanih pandemijom Kovid 19, dok će se

\footnotetext{
${ }^{2}$ Slične analize međunarodnih zbivanja, za koje smo smatrali da mogu biti korisne u osmišljavanju dalekovidih javnih politika i posebno dalekovide spoljne politike Srbije, prezentovali smo i u našim prethodnim radovima od kojih je posebno važan rad: Neven Cvetićanin, „Kuda ide svet? Analiza društveno-političkih procesa koji opredeljuju globalna zbivanja na početku 21. veka", u: Globalizacija i izolacionalizam, Institut društvenih nauka - Centar za ekonomska istraživanja, Beograd, 2017.

${ }^{3}$ Termin Realpolitik je nemačkog porekla i skovan je u bizmarkovskoj Nemačkoj u drugoj polovini 19. veka kako bi legitimizovao pragmatičan pristup politici koji je praktikovao „gvozdeni“ nemački kancelar, koji je do krajnjih konsekvensi doveo realistički obrazac politike definišući je kao „veštinu mogućeg“. O ovom realističkom obrascu politike pre i posle Bizmarka u knjigama: Neven Cvetićanin, Politička mehanika i veština državništva, Institut društvenih nauka, Arhipelag, Beograd, 2016; i Neven Cvetićanin, Državništvo modernog doba, Institut društvenih nauka, Arhipelag, Beograd, 2016.
} 
drugi baviti Srbijom i regionom Balkana, pokušavajući da prozre kako se ovaj širi proces (opisan u prvom delu rada), refelektuje na naš region.

\section{Kako je pandemija Kovid 19 od Evrope ponovo napravila strateškog mislioca?}

Eksplicitni povratak tzv. real-politike i tzv. politike moći na evropski kontinent nije izazvan pandemijom Kovid 19, već se ovaj proces mogao uočiti i ranije, iako ga je pandemija nesumnjivo ubrzala i zaoštrila. Da se proces mogao uočiti i par godina pre izbijanja pandemije Kovid 19 bilo je eksplicitno vidljivo iz izjava najviših zvaničnika evropskih vlada, što je ukazivalo na novu stratešku činjenicu koja je početkom prethodne decenije bila nezamisliva. Ona se najbolje ogleda u izjavi nemačkog ministra spoljnih poslova Heika Masa (Heiko Mass), iz 2018. godine, koji je izjavio da je „krajnje vreme da se preispita transatlantsko partnerstvo na trezven, kritičan, pa čak i na samokritičan način" usled čega je najavio da će izaći sa „planom nove spoljne politike Berlina prema SAD“ kako bi se stvorila „snažna i nezavisna Evropa, koja treba da bude protivteža SAD svaki put kada Vašington pređe crvenu liniju“. ${ }^{4}$ Ova izjava je data u vreme Donalda Trampa (Donald Trump) kao američkog predsednika, ali je geopolitička činjenica da ni dolazak nove administracije Džoa Bajdena (Joe Biden) nije uspeo da vrati transatlantske odnose tamo gde su oni bili početkom prethodne decenije - u potpuni sklad i harmoniju.

Nesumnjivo je prethodno citirana izjava nemačkog ministra spoljnih poslova izazvana promenom spoljne politike administracije tadašnjeg američkog predsednika Donalda Trampa prema Nemačkoj i Evopskoj uniji u celini u odnosu na ranije američke administracije, koje su još od kraja Drugog svetskog rata i čuvenog „Maršalovog plana“, s kraja četrdesetih godina 20. veka, tretirale Nemačku i Zapadnu Evropu kao „mezimca“ kome treba pomoći da se oporavi od ratnih razaranja kako bi predstavljao "mlađeg partera" transatlantskog partnerstva i tampon zonu prema sovjetskoj Rusiji. U međuvremenu je Nemačka, ponovno se ujedinjujući, toliko ojačala, pogotovo

\footnotetext{
4 "Nemački ministar spoljnih poslova: Vreme je da partnerstvo sa Amerikom bude preispitano", Blic, 27.8.2018, Internet, https://www.blic.rs/vesti/svet/nemacki-ministarspoljnih-poslova-vreme-je-da-partnerstvo-sa-amerikom-bude/qz4p1dj, 29/08/2018.
} 
u ekonomskoj ravni, da je od „mlađeg“ postala skoro ravnopravan, suviše jak partner (pogotovo u ekonomskoj ravni), komandujući uz to panevropskom političko-ekonomskom organizacijom kakva je Evropska unija, dodatno jačajući i ekonomski i politički i strateški, usled čega se odnos snaga između prekookeanskih „transatlantskih partnera“ veoma promenio u odnosu na vreme Maršalovog plana, što je vidljivo posebno u ovoj „političkoj deceniji“. Nemačka više nije ratni gubitnik i mirnodopski mezimac koji je kao „mlađi partner" zgodan tek da pasivno tercira američkom „prvom glasu“, već je (ponovo) izrasla u kontinentalnu silu koja svojom ekonomskom snagom određuje takt Starom kontinentu, bivajući uz to i veoma ambiciozna u globalnoj ekonomiji, potiskujući u njoj korak po korak svoje dojučerašnje prekookeanske „partnere“ kojima je donedavno sve lošije išlo po pitanju ekonomskih parametara, i koji su sve lošije stajali upravo u onim realnim industrijskim ekonomskim sektorima u kojima je Nemačka stajala sve bolje.

Retorika, koju je u svojoj predizbornoj predsedničkoj kampanji koristio 2016. godine Donalad Tramp, izazvana je upravo realnom promenom u transatlantskim odnosima u kojima je ekonomska komponenta konkurencije između SAD i Evrope počela da ugrožava njihovo strateško partnerstvo, jer birači u SAD, kao i birači svuda širom sveta, ne razmišljaju o strateškim stvarima već prvenstveno o svojim ekonomskim perspektivama. Trampov tim je tada ovu činjenicu dobro uočio i pragmatično eksploatisao tokom kampanje na kraju koje su u novembru 2016. godine odneli pobedu, najavljujući set novih politika koje je prethodna Trampova administracija čitavog svog mandata pokušavala da sprovede, nekad s više, nekad s manje uspeha. Nova administracija Džoa Bajdena očigledno mnogo više misli strateški a nešto manje ekonomski, vraćajući se onom polu američke spoljne politike koji je oduvek bio svestan da status strateške supersile košta, i koji nije bio sklon da poistoveti strategiju sa ekonomijom, iako je i ta škola mišljenja morala poštovati golu činjenicu da je u svetu u kojem živimo geopolitika zapravo sve više geoekonomija.

Trampova pobeda na predsedničkim izborima u SAD, u novembru 2016. godine, upravo je bila reakcija na izmenjenu geoekonomsku situaciju $u$ odnosima SAD i Evrope i činjenice da je nakon početka svetske ekonomske krize, krajem prve decenije 21. veka, svako krenuo da „spašava“ sopstvenu ekonomiju, što se pre ili kasnije moralo odraziti na transatlantske odnose.

Tako je prvi korak u povratku tzv. real-politike (Realpolitik) i tzv. politike moći (Machtpolitik) u svetske odnose i na evropski kontinent, nakon četvrt veka 
trijumfa liberalne paradigme, bio početak svetske ekonomske krize krajem prve decenije 21. veka koji je ogolio geoekonomske odnose, uzrokujući niz združenih ekonomskih, strateških i konačno političkih promena. Do izbora Donalda Trampa za predsednika SAD bilo je slučajeva da predstavnici politika koje su opozitne liberalnim trijumfuju u različitim zemljama i miljeima, ali činjenica da se sa Trampom to desilo u samom središtu globalnog sistema pokazuje da se sam taj sistem menja u svome središtu, a ne tek na periferiji, demostrirajući da je promena zapravo strukturalna i da je reč o procesu, a ne o nizu nepovezanih slučajnosti. Naivno bi bilo misliti da puka promena administracije u SAD može zaustaviti taj proces, i da administracija Džoa Bajdena može američke unutrašnje i spoljne odnose restartovati na konstante vremena Barka Obame ili Džordža Buša Mlađeg.

Proces je dubinski i realan i u ovome radu smo ga detektovali kao proces povratka tzv. real-politike (Realpolitik) i tzv. politike moći (Machtpolitik) u svetske odnose, što je posebno bilo vidljivo usled pandemije Kovid 19 i globalnog „geopolitičkog lockdown-a“, kada se u uslovima pandemije jasno ocrtalo nekoliko geopolitičkih celina koje su se „zatvorile“. Anglosaksonska (tzv. Five Eyes), evropska, ruska i kineska geopolitička celina su se pred opasnošću pandemije Kovid 19 prirodno zatvorile, što je bilo posebno vidljivo u samoodrživom načinu proizvodnje i distrubucije vakcina protiv Kovid 19, u čemu je Evropa tj. evropska geopolitička celina opet bila u najneprijatnoj situaciji, jer je ponovo morala da uči da misli strateški, obezbeđujući samodovoljnost u strateškim resursima poput proizvodnje vakcina. Proces koji se začeo sa početkom pandemije Kovid 19 uzrokovao je da se danas Evropska unija vraća tzv. strateškoj reindustrijalizaciji tj. povratku proizvodnje strateških resursa na svom tlu, što najbolje svedoči o tzv. "geopolitičkom lockdowwn-u“ kojem prisustvujemo od pojave pandemije Kovid 19.

Ovo mutiranje nedestilisanih i do juče šarolikih međunarodnih odnosa u destilisanu, „,̌̌istu“ geopolitiku, odnosno real-politiku ili politiku moći, neće biti ništa drugo nego specifični spoj geopolitike, geoekonomije i geostrategije kojim će velike sile pokušati da u situaciji nestabilnosti i transformacije svetskog sistema izazvanih pandemijom, obezbede sopstvenu ekonomsku, političku i stratešku samoodrživost i sigurnost, prelazeći od seta liberalnih ka setu mera tzv. politike moći. ${ }^{5}$

\footnotetext{
${ }^{5}$ Sintagmu svetski sistem, kao i tezu da ovaj "svetski sistem" ima svoju spoznatljivu ekonomsku i političku logiku koja omogućuje aproksimativne analitičke predikcije
} 
Ovo se najbolje očituje iz početka procesa reindustrijalizacije strateških resursa Evrope, koji je započeo upravo usled pandemije Kovid 19, pa možemo metaforično reći da je pandemija Kovid 19 od Evrope, tj. Evropske unije, ponovo napravila strateškog mislioca koji je postao svestan svoje strateške ranjivosti i koji je počeo da preduzima mere da je smanji i prevaziđe.

Budući da je čitav proces „povratka geopolitike“ u svetske odnose objektivan i zakonit (ako je ona uopšte iz njih ikada i nestala), on je pre ili kasnije morao doći i u Evropu, a pandemija Kovid 19 je taj proces samo ubrzala i ogolila, jer u situacijama svetskih kriza, bez obzira da li su vojne (ratovi), ekonomske (recesije i depresije) ili zdrastvene (pandemije i epidemije) strateška pitanja imaju prednost nad taktičkim. Tako je i Evropa ponovo pronašla svoj talenat za strateško razmišljanje, iako ostaje veliko pitanje njenih realnih strateških kapaciteta i njihove organizacije No, problem je propoznat i evropski stratezi uveliko rade na njegovom rešavanju. ${ }^{6}$

lako Evropa od svetskih ratova ne predstavlja središte svetskog sistema, kao što ga je u kontinuitetu oličavala nekoliko vekova ranije, pa je i za očekivati da u 21. veku bude neka vrsta "geopolitičke periferije“, budući da se istorija seli u jugoistočnu Aziju gde će u biti najužarenije geopolitičke tačke, Evropa u svetskim odnosima još uvek ima autoritet "Stare dame" koja je i stvorila moderni međunarodni diplomatski poredak. Stoga joj u vremenu globalnog povratka geopolitike ostaje upravo njena stara uloga čuvara globalne ravnoteže snaga, koju joj je nekoć namenio De Gol, što ona može ispuniti samo ako se posveti sopstvenoj strateškoj samodovoljnosti, koja zbog njene pozicije i specifične povezanosti sa SAD (u vojnom), Kinom (u ekonomskom) i Rusijom (u energetskom pogledu) nikad ne može biti apsolutna. Ipak, ova pozicija višestruke povezanosti sa drugim geopolitičkim silama daje joj mogućnost da u 21. veku bude čuvar svetske geopolitičke ravnoteže.

budućnosti preuzeli smo iz; Immanuel Wallerstein, The Modern World-System I: Capitalist Agriculture and the Origins of the European World-Economy in the Sixteenth Century, Academic Press, New York, 1974.

${ }^{6}$ Na međunarodnoj konferenciji Strateški tokovi 2021, koju je u Beogradu početkom leta 2021. organizovao Forum za strateške studije (FORST), jedan od govornika je bio Stiven Blokmans (Steven Blockmans), direktor CEPS-a, jednog od najvećih evropskih think tankova, koji je najveći deo svog izlaganja upravo posvetio ovom procesu reindustrijalizacije strateških resursa Evrope. Snimak konferencije Strateški tokovi 2021. je na linku: https://www.facebook.com/122606531149076/videos/911989842691995, 07/07/2021. 
Samosvešćivanju uloge Evrope kao čuvara svetske geopolitičke ravnoteže svakako je doprineo čitav proces „povratka geopolitike“, odnosno proces „povratka real-politike“ u svetske odnose. Posebno je doprinela pandemija Kovid 19 i problemi koje je ona izazvala, a koji nisu bili dominantno zdrastveni, već su postali bezbednosni i strateški, menjajući evropsko političko polje i pomerajući ga od seta liberalnih politika ka setu mera tzv. real-politike, poput pomenutog procesa reindustrijalizacije evropskih strateških kapaciteta. I dok je pomeranje političkog polja u Evropi od seta liberalnih ka setu mera realpolitike po pitanju migrantske krize bilo karakterističnije za manje članice EU, poput zemalja Višegradske grupe, u pogledu reakcije na pandemiju Kovid 19, ono je postalo očigledno kod najjačih članica Evropske unije, poput Nemačke i Francuske, kao i kod same EU administracije u Briselu koji su zajednički lansirali projekat tzv. evropske strateške autonomije, čiji konkretni dometi ostaju još uvek nepoznati. Velika Britanija je još ranije, Bregzitom, obezbedila svoju "stratešku autonomiju“, što potvrđuje našu tezu da prisustvujemo svojevrsnom geopolitičkom lockdown-u, odnosno svojevrsnom „zaključavanju“ raznih geopolitičkih prostora, što se moglo uočiti i pre pandemije Kovid 19 (kada se zapravo desio Bregzit), ali što je posebno uzelo maha tokom pandemije.

Projekat tzv. evropske strateške autonomije je zapravo stara De Golova ideja koju je u novim okolnostima reaktuelizovao De Golov naslednik na mestu predsednika Francuske - Emanuel Makron (Emmanuel Macron). U svojim izjavama, pre pandemije Kovid 19, predsednik Francuske pozvao je zemlje EU da u odnosu sa ostalim geopolitičkim silama zaštite svoje interese i da se više oslanjaju na sopstvene strateške resurse. ${ }^{7}$ Ono što je pre pandemije Kovid 19 bilo puka strateška intuicija, tokom pandemije je postalo jasna strateška ideja, ma koliko ona imala ograničene kapacitete u realnosti.

Makronovu prethodno citiranu "degolističku“ izjavu sigurno ne treba tumačiti kao neki definitivan raskid Francuske i EU sa SAD, što bi bilo nerealno očekivati u ovom momentu kada još postoje snažne spone transatlantskog partnerstva, prvenstveno u vojnoj saradnji u okviru NATO, već pre kao neku vrstu "geopolitičkog cenkanja“ u smislu upozorenja da će EU, predvođena

7 "Makron: EU da se ne oslanja samo na SAD, partnerstvo sa Rusijom", Radio Slobodna Evropa, 28. 8. 2018., Internet: https://www.slobodnaevropa.org/a/makrn-eu-bezbednost -nato-rusija/29457577.html, 31/08/ 2018. 
Francuskom i Nemačkom, ostaviti sebi prostora da sklapa autonomne geoekonomske aranžmane. ${ }^{8}$

U kontekstu naše teme ovo potvrđuje hipotezu koju branimo od početka rada - da prisustvujemo vremenu povratka geopolitike u svetske odnose (ako je ona uopšte iz njih ikad i odlazila), odnosno povratku tzv. real-politike i da je ovaj proces Kovid 19 pandemija samo ogolila i dodatno ubrzala, što je najbolje vidljivo iz svojevrsnog "geopolitičkog lockdown-a“, odnosno "zatvaranja“ različitih geopolitičkih prostora usled pandemije.

Početkom treće decenije 21. veka, svaki politički i ekonomski entitet, bez obzira da li je državni, međunarodni ili korporativni, potonuo ponovo u realpolitiku, koristi sva sredstva koja poseduje kako bi poboljšao svoj ukupan strateški položaj. U takvoj situaciji, nekadašnja klasična geopolitika zapravo mutira u svoj oblik primeren 21. veku - u geoekonomiju, te u pratećim globalnim geoekonomskim nadgornjavanjima svako radi ono što može bez mnogo obzira prema globalnim konkurentima i svako bira strategije prema sopstvenim snagama i mogućnostima. Tako se ponaša odskora i Evropska unija koju je pandemija Kovid 19 strateški osvestila i od koje je ponovo napravila „strateškog mislioca“.

Dok su najznačajnije sile poput SAD, Kine i Rusije u drugoj deceniji 21. veka, u potpunosti stupile sa ideološkog na suvoparni i nemilosrdni teren real-politike, krajem druge i početkom treće decenije novog milenijuma to je učinila i tzv. „stara Evropa“, usled izbijanja Kovid pandemije. Ispostavilo se da se Evropa, za razliku od jačih geopolitičkih celina (SAD, Kine i Rusije), zatekla u svojevrsnoj geopolitičkoj stešnjenosti, što je bilo vidljivo iz organičene sposobnosti Evropske unije da organizuje proizvodnju i distribuciju vakcina za sopstvene građane, upravo u vremenu u kojem se geopolitička snaga svakog entiteta merila upravo ovim kapacitetom, u skladu sa opisanom, „geopolitici vakcina“.

Stari kontinent i Evropska unija kao njegov aktuelni dominantni panevropski institucionalni izraz su uopšte u izvesnom geopolitičkom sendviču, jer predstavljaju ekonomskog džina ali bezbednosnog i strateškog patuljka, usled čega su vodeći stratezi Evropske unije došli do zaključka da je potrebno da ojačaju sopstvene strateške kapacitete, prvenstveno u geoekonomskoj ravni.

Evropska unija je prethodnih godina više bila objekt nego subjekt glavnih globalnih geopolitičkih i geoekonomskih dešavanja, jer se nalazila u

\footnotetext{
${ }^{8}$ Poput onog kojeg je krajem 2020. sklopila sa Kinom, ili onog koji je još ranije, u nekoliko mahova i projekata (od Severnog toka (I) do Severnog toka II) sklopila sa Rusijom.
} 
svojevrsnom geopolitičkom sendviču u koji ju je posebno stavila pandemija Kovid 19, što je bilo vidljivo usled njene nemogućnosti da u „geopolitici vakcina" - globalnom nadmetanju geopolitičkih super sila da preko procesa proizvodnje i distribucije vakcina pokažu sopstvenu moć - odreaguje spremno i efikasno. No, pandemija Kovid 19 pokazala je i da je Evropska unija svesna ovog problema, usled čega je krenula u svojevrsnu reindustrijalizaciju svojih strateških kapaciteta - tzv. stratešku reindustrijalizaciju, odnosno u obnovu svojih strateških kapaciteta prvenstveno u (geo)ekonomskoj ravni, a ostaje tek da se vidi da li EU ima snage i za nešto više.

Naime, budući da je EU sa svojim velikim i malim članicama, ukupno gledajući, poslednjih godina u svojevrsnom geopolitičkom sendviču i da je rastrzana između globalnih geopolitičkih supersila koje se upravo na području EU bore za uticaj (pre svih SAD, Kine i Rusije), možemo pretpostaviti da će od konstelacije odnosa ovih velikih geopolitičkih sila i njihovih dogovora, i eventualnih konflikata, zavisiti stabilnost same EU. Evropska unija je ovaj problem upravo usled pandemije Kovid 19 prepoznala i čini trenutno sve da u sopstvenu građevinu doda dovoljno strateškog armiranog betona, kako je borba ostalih geopolitičkih supersila na njenoj teritoriji ne bi mogla destabilizovati.

No, Evropska unija je takoreći već podeljena na različite „klubove“ u kojima veći uticaj imaju neke od pomenutih globalnih geopolitičkih sila nego sama EU, kao što je, na primer, slučaj sa tzv. „novom Evropom“ (posebno Poljskom, Rumunijom i baltičkim državama) koja je trenutno bliža Vašingtonu nego Briselu, kao neka vrsta štita prema Rusiji, prema kojoj Brisel još nije siguran kako da se postavi. Ovo svedoči da Evropa nije samo u geopolitičkom sendviču, već i da je kao posledica ovakve pozicije postala poprište borbe različitih geopolitičkih interesa koji je time nesumnjivo mogu destabilizovati i ograničiti njen kapacitet za proširenje, što može tangirati naš region i posebno Srbiju, čime ovo postaje važna tema za proučavanje i istraživanje institucija naše države, te je naš rad u tom smislu prilog razumevanju ove važne teme i prilog naučnoj potpori javnim politikama, kako bi na osnovu objektivnih a ne ideologizovanih analiza mogle da donose odluke. ${ }^{9}$

\footnotetext{
${ }^{9}$ Veoma korisna analiza mogućih dešavanja u budućnosti na relaciji Srbija-EU, u ovome smislu naučnoistraživačke podrške javnim politikama je ponuđena u: Duško Lopandić, Moguća Evropa i godine pred nama; Evropska unija, Srbija i svet u promenama-osvrti $i$ ogledi, Institut za evropske studije, Beograd, 2018.
} 
Dakle, zaključak prvog dela našeg rada je da je Evropska unija upravo usled pandemije Kovid 19 potpuno postala svesna svojih strateških slabosti, te je započela veliki proces podizanja sopstvenih strateških kapaciteta, prvenstveno u geoekonomskoj ravni, budući da je kao mirovni projekat još od druge polovine 20. veka napustila ambicije da bude klasična vojna strateška sila. Evropska unija je upravo usled pandemije Kovid 19, metaforično govoreći, ponovo postala strateški mislilac. Doduše, za sada uglavnom nenaoružan, za razliku od ostalih strateških supersila našeg vremena.

Konačno, buduća stabilnost Evropske unije bez sumnje će zavisiti od mogućnosti da EU predvođena osovinom Berlin-Pariz razvije sopstvenu bezbednosnu politiku, odnosno tzv. evropsku stratešku autonomiju u punom geopolitičkom, a ne samo u geoekonomskom kapacitetu. Ovo u jednačinu budućnosti Evropske unije dovodi još nepoznatih faktora, koji otežavaju objektivno predviđanje koliko proces evropske strateške autonomije uopšte može daleko da odmakne.

Sa sigurnušću možemo očekivati da će Evropska unija u narednim godinama ojačati svoje strateške kapacitete, prvenstveno u oblasti strateških industrija poput zdrastvene, namenske i IT industrije, ali je sada nezahvalno prognozirati koliko će čitav proces napredovati i da li će iz geoekonomske preći i u „čistu“ geopolitičku oblast.

\section{Posledice pandemije po kapacitet Evropske unije za proširenje i po evropsku perspektivu Srbije i regiona}

Od načina na koji će Evropska unija i njeni dominantni nacionalni centri amortizovati u prethodnoj celini opisanu situaciju strateške stešnjenosti u svojevrsnom geopolitičkom sendviču i nedostatka strateške samodovoljnosti, zavisiće kapacitet EU za proširenje na naš region a time i pozicija države Srbije u svim prethodno opisanim procesima.

Imajući u vidu sve što smo izložili u prvoj celini našeg rada, možemo reći da će na kapacitet Evropske unije za proširenje dominantno uticati nekoliko faktora:

1. geopolitički faktor - odnos između pomenutih dominantnih geopolitičkih globalnih sila (SAD, Kina, Rusija, EU) i njihov potencijal i interes za stabilnom, odnosno nestabilnom EU 
2. geoekonomski faktor - pandemija Kovid 19 i njene pre svega ekonomske, ali i političke posledice u Evropi

3. regionalni faktor - odnosi između evropskih i regionalnih političkih elita i sposobnost regionalnih elita da sprovedu tražene institucionalne reforme na putu ka EU, kao i sklonost regionalnih elita za povezivanjem sa drugim geopolitičkim silama poput Rusije, Kine, SAD i Turske i eventulna mogućnost u tom smislu strateške kolizije regiona i njegove zaglavljenosti u svojevrsnom strateškom limbu

Konačno, na kapacitet Evropske unije za proširenje dominantno će uticati i stav elita EU o daljem proširenju, kao i stav građana EU koji će biti jasniji nakon saveznih izbora u Nemačkoj početkom jeseni 2021, i predsedničkih i parlamentarnih izbora u Francuskoj na proleće 2022, kada će se već moći preciznije utvrditi u kojem pravcu ide Unija i njena glavna strateška osovina Berlin-Pariz. Ono što možemo trenutno reći jeste da su pred nama dve solucije:

Prva je zamor materijala i kod elita i kod građana Evropske unije, koji bi pod uticajem prethodno pobrojanih faktora u budućnosti bili sve manje skloni proširenju EU.

Druga solucija je da se ipak pristupi ubrzanom proširenju Evropske unije na Balkan i one njegove države koje su ostale izvan EU, kako bi se time neutralisao efekat Bregzita i kako bi se pokazalo da je Unija i dalje vitalna i sposobna da se širi, ali i kako bi se time pacifikovala potencijalna „balkanska Ahilova peta" koja može biti posebno neugodna za Evropu u situaciji stešnjenosti u geopolitičkom sendviču kao potencijalni izvor nestabilnosti, budući da je Balkan bio i ostao granična teritorija na kojoj se ukrštaju različiti geopolitički interesi izazivajući krizne situacije.

Druga solucija zavisi i od sposobnosti Evropske unije da bude pravičan medijator u nivelisanju interesa država koje su proistekle iz bivše Jugoslavije, bez favorizovanja jednih država na štetu drugih, jer i ove države, usled opšteg trenda „geopolitičkog cenkanja“ kome uglavnom podleže čitav prostor između La Manša na jednoj i Rusije i Kine na drugoj strani, mogu pribeći ovoj strategiji geopolitičkog cenkanja ukoliko bi smatrale da za njihove nacionalne interese postoji bolja alternativa od pripadnosti Evropskoj uniji. ${ }^{10} \mathrm{U}$ svetu u kojem postoji

${ }^{10}$ Duško Lopandić u svojoj knjizi argumentuje da članstvo u Evropskoj uniji, čak i u promenjenim globalnim okolnostima, donosi više koristi nego štete zemljama male i srednje veličine poput Srbije; Duško Lopandić, Moguća Evropa i godine pred nama; 
sve manje principijelnih saveza, i u kojem svako na prvom mestu brine o sopstvenoj bezbednosti i spokoju, niko ne bi mogao zameriti balkanskim državama ukoliko bi se ponašale pragmatično i u skladu sa sopstvenim nacionalnim interesima poput, na primer, zemalja Višegradske grupe, prosuđujući na osnovu njih strateška partnerstva koja su im dugoročno povoljna.

Usled svega toga, ne može se sa sigurnošću reći da će se proces pridruživanja regiona i Srbije Evropskoj uniji završiti do 2025/2026. godine, kako je proklamovano strategijom proširenja iz 2018, jer u ovom momentu ne znamo kako će u pomenutim „ciljanim“ godinama izgledati Evropska unija i njena geopolitička konfiguracija, kao i ukupna konfiguracija našeg regiona. Stoga je ovo jednačina sa dve nepoznate, što komplikuje izglede za njeno dogledno uspešno rešavanje i precizno predviđanje procesa pred nama. Ono što možemo, međutim, sada preciznije reći o tome jeste da bez obzira da li će se naš region u potpunosti integrisati u EU ili ne - i jedna i druga solucija biće uslovljene geopolitičkim razlozima. Jednostavno govoreći, ako region „uđe“ ili ako ne „uđe" u EU, i jedno i drugo rešenje biće uslovljeno širim geopolitičkim projekcijama i konstelacijama.

No, kakav god da bude razvoj događaja u odnosima između našeg regiona i EU, našem društvu bi svakako bilo korisno da nastavi sa procesom svog institucionalnog uređenja koje je započeto u procesu pridruživanja EU, zvali se takvi procesi "evropeizacijom“ ili nekako drugačije. Možda bi termin „evropeizacija“ trebalo zameniti terminom „institucionalizacija“, kako bi se stavio naglasak na potrebu da se društvo i država urede i modernizuju zbog samih sebe, kako bi opstali u surovom svetu real-politike koji smo opisali u prvom delu rada. Proces institucionalizacije i modernizacije društva bi se ovako počeo doživljavati kao vrednost po sebi, koja je neophodna za preživljavanje srpskog društva u dinamičnom svetu koji sve više ubrzava što 21. vek više odmiče.

Jednostavno govoreći - ovo znači pripremiti društvo i državu da kao moderno organizovan entitet egzistiraju u dinamičnom svetu današnjice, bez obzira šta će se u konačnici desiti sa procesom pridruživanja Srbije Evropskoj uniji, koristeći pak pragmatično zamajac ovog procesa, dok god on traje, da se društvo

Evropska unija, Srbija i svet u promenama - osvrti i ogledi, op. cit., str. 51-56. Pri čemu treba podsetiti da Srbija, za razliku od drugih zemalja slične veličine, ima specifičan „kosovski čvor“ čije će (ne)popuštanje bez sumnje značajno uticati na dugoročan odnos između Srbije i EU i šanse da Srbija jednog dana zaista postane punopravan član EU. 
institucionalno uredi u pravcu vladavine zakona i pravne države. Pravna sigurnost i vladavina zakona je ono što očigledno najviše treba balkanskim državicama proisteklim iz bivše Jugoslavije, pa time i Srbiji, da bi bile države u punom kapacitetu i da bi uspešno opsluživale potrebe društva, baš kao što je slučaj u većini evropskih država koje još uvek predstavljaju najbolje mesto za život na svetu kada se uzme ukupan nivo građanskih, socijalnih i ekonomskih prava i sloboda. ${ }^{11}$

Stoga je manje bitno da li će Srbija postati punopravan član Evropske unije, iako bi to za nju nesumnjivo predstavljao značajan strateški uspeh, dok je mnogo bitnije da svojom strukturom počne da liči na uređene evropske zemlje. Fenomen balkanskih država poput Rumunije i Bugarske koje su postale punopravne članice Evropske unije, a nastavile da pate od mnogih starih antiinstitucionalnih bolesti anarhičnog pretpolitičkog poretka dobro je poznat i svakako ne predstavlja dobar primer za Srbiju. Za Srbiju je bolji primer uspešnih i kredibilnih evropskih država poput, na primer, Norveške, Islanda ili Švajcarske koje nisu eksplicitne članice Evropske unije, ali imaju sa njom saglasan sistem i različite oblike tzv. privilegovanog partnerstva.

Ne ulazeći ovde u različitost geopolitičkog položaja Srbije i pomenutih država, različitost njihovog istorijskog nasleđa i, shodno svemu prethodnom, različitost mogućnosti da implementiraju slične institucionalne unutrašnje i spoljne politike, čime smo se delimično bavili u nekim od naših prethodnih radova,, ${ }^{12}$ možemo reći da tzv. „evropeizacija“ Srbije treba da predstavlja zapravo njenu institucionalizaciju i modernizaciju, pre svega u pravcu vladavine zakona, pravne države i tzv. socijalno-tržišne privrede, što je standard uređenih evropskih država, bez obzira da li su one eksplicitne članice Evropske unije ili sa EU imaju neku drugu vrstu odnosa.

\footnotetext{
${ }^{11}$ O ekonomskom, socijalnom i političkom sistemu „države blagostanja“ koji je prisutan u najvećem broju država EU i posebno u njenim najuspešnijim članicama poput Nemačke, Austrije i skandinavskih država, a koje bi, uz svu različitost kultura, bilo dobro da budu egzemplar Srbiji što se tiče unutrašnje institucionalizacije, bez obzira na strateške izbore spoljne politike Srbije, u studiji; Rolf Hase, Herman Šnajder, Klaus Vajgelt, Leksikon socijalne tržišne privrede, Fondacija Konrad Adenauer, Beograd, 2005. O genezi ovog "sistema blagostanja" u: Neven Cvetićanin, Državništvo modernog doba, op. cit.

${ }^{12}$ Neven Cvetićanin, Aleksandar Đokić, "Security position of Serbia in Europe today concept of security neutrality and options of modeling Serbian neutrality according to Swiss neutrality model", u: Thematic conference proceedings of international significance Archibald Reiss Days, Volume II, Policijska akademija, Beograd, 2015.
} 
Srpsko društvo nema više luksuz da se vezuje za ultra-ideološke projekte, kao što je često bio slučaj u prethodna dva veka naše državnosti, jer se time izlaže riziku da takvi projekti propadnu a da iza njih ostane ogoljena suštinska nerazvijenost društva i neuređenost države. Stoga ono nema luksuz da „evropeizaciju“ shvati ideološki i fiksira se za procese koji su neizvesni, već „evropeizacija" treba da bude shvaćena pragmatično kao institucionalizacija i modernizacija srpskog društva u pravcu najpoželjnijih evropskih standarda uređenja društva, bez obzira na eksplicitno članstvo u Evropskoj uniji, koje je bez sumnje za Srbiju i dalje treba da ostane eksplicitan strateški cilj. No, ovom strateškom cilju sada samo treba pridodati unutrašnje strateške osigurače, a nema boljeg „osigurača" za sve scenarije budućnosti od uređenog i institucionalizovanog društva i države.

Stoga je srpskom društvu i državi, umesto bilo kakvih isforsiranih ideoloških projekata neke apstraktne „evropeizacije“, potrebno da u vrlom novom-starom svetu real-politike postupa real-politički, koristeći zamajac pridruživanja Evropskoj uniji kad god on pomaže uređenju države i društva, shvatajući ga kao sredstvo uređenja a ne kao neki „sudbinski“ rigidni apstraktni cilj. Jednostavno govoreći, proces EU integracija je dobar sve dok koristi nacionalnim interesima, od čega su institucionalizacija, modernizacija i konstituisanje pravne države i vladavine zakona nesumnjivo veliki i trajni nacionalni interesi, još od formiranja moderne srpske države u 19. veku.

Naposletku, u vremenu u kojem, kao što smo izložili u prethodnim delovima rada, prisustvujemo „povratku geopolitike“, odnosno povratku tzv. real-politike i tzv. politike moći u svetske odnose, Srbija proces evropskih integracija treba da shvata više pragmatično nego ideološki, razumevajući glavne strateške tokove koji su na snazi nakon pandemije Kovid 19 na našem kontinentu i šire. Ovaj rad je prilog tom razumevanju pomenute problematike i prilog mogućnosti da se na bazi ovog razumevanja i njegovih pratećih uvida kreiraju održive spoljnopolitičke pozicije naše države.

\section{Literatura}

Cvetićanin, Neven, Aleksandar, Đokić, "Security position of Serbia in Europe today - concept of security neutrality and options of modeling Serbian neutrality according to Swiss neutrality model", u: Thematic conference 
proceedings of international significance Archibald Reiss Days, Volume II, Policijska akademija, Beograd, 2015.

Cvetićanin, Neven, Politička mehanika i veština državništva, Arhipelag, Institut društvenih nauka, Beograd, 2016.

Cvetićanin, Neven, Državništvo modernog doba, Arhipelag, Institut društvenih nauka, Beograd, 2016.

Cvetićanin, Neven, „Kuda ide svet? Analiza društveno-političkih procesa koji opredeljuju globalna zbivanja na početku 21. veka", u: Globalizacija i izolacionalizam, Institut društvenih nauka, Centar za ekonomska istraživanja, Beograd, 2017.

Hase, Rolf, Šnajder, Herman, Vajgelt, Klaus, Leksikon socijalne tržišne privrede, Fondacija Konrad Adenauer, Beograd, 2005.

Lopandić, Duško, Moguća Evropa i godine pred nama; Evropska unija, Srbija i svet u promenama - osvrti i ogledi, Institut za evropske studije, Beograd, 2018.

Wallerstein, Immanuel, The Modern World-System I: Capitalist Agriculture and the Origins of the European World-Economy in the Sixteenth Century, Academic Press, New York, 1974. 


\title{
THE EUROPEAN UNION IN THE GLOBAL “GEOPOLITICAL LOCKDOWN" AND THE BEGINNING OF THE PROCESS OF STRATEGIC REINDUSTRIALIZATION OF THE EU
}

\begin{abstract}
The paper presents an attempt to offer an objective analysis of dominant geopolitical processes in Europe at the time of the COVID-19 pandemic and to place these processes in an objective global geopolitical context. In this sense, the paper describes the return of so-called real politics and the so-called power politics in world relations as the main consequence of the pandemic in Europe and the world. This can be seen from a wider process of "geopolitical lockdown" which followed the COVID-19 pandemic in a geopolitical sense all around the world. The paper explores the consequences of this process in Europe and the Balkans, and in particular on the European Union's enlargement capacity, which is at the moment a top priority issue for Serbia as a state and society. Therefore, the analysis offered in this paper can be useful for conceptualizing public policies in Serbia and designing a realistic approach to the process of European integration in view of possible developments in Europe after the pandemic of COVID-19.

Keywords: Europe/EU, pandemic, COVID-19, consequences, geopolitics, lockdown, real-politics, Balkans, Serbia, EU enlargement.
\end{abstract}

